\section{EMERGENCIES IN MEDICAL PRACTICE}

Edited by C. Allan Birch, M.D., F.R.C.P. 2nd

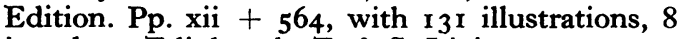
in colour. Edinburgh: E. \& S. Livingstone. 1950. 27s. 6d.

C. Allan Birch and his 21 associates have made this book much more than its title would suggest. One feels that it is a compromise between a textbook of medicine, an index of differential diagnosis, and a primer of up-to-date therapeutics. To the reader who is suspicious of the word compromise may it be said at once that it is a most successful one.

It is quite apparent in every section that the contributors have refrained from recommending many of the time-honoured and obsolete practices still referred to in some of the more academic textbooks of medicine, and have stressed the really useful treatments and methods that are applied today in any first rate hospital or general practice.

The range of subject matters discussed in a precise and lucid manner is enormous. The diligent reader will there find most useful information on such widely different topics as mushroom poisoning and the practice of embalming, the dangers of bronchography and the acute abdomen 'at sea', the causes of epileptiform attacks and the use of modern anticoagulants -including Tromexan, etc., etc. One is particularly impressed with such short and extremely common-sense sections as one on "What to tell the patient who has a fatal disease' or 'On what to do when there is little to be done.'

Comparisons are invidious. This volume will certainly become to the physicians and practitioners what Pye's Surgical Handicraft has been for some years to the surgeons. A most valuable companion and stand-by, essential in every medical man's library, and above all a pleasure to read.

F.W.W.

\section{ADVANCES IN SURGERY, Vol. 2}

Edited by William de Witt Andrus, et al. Pp. xii +590 , illustrated. London and New York: Interscience Publishers. I 949. Price 88s.

'The second volume of 'Advances in Surgery' is as good as the first, which is praise indeed. The reason that the high standard has been maintained is accounted for, on the one hand, by the zeal of the chairman, and on the other by the eminence of the members of the editorial board who represent the best in surgery in the United States, Canada, Great Britain and Sweden.

The I I chapters which compose this new volume range through the whole of general surgery including that of the central nervous system. By devoting sections to such subjects as the oesophagus, hypertension, pancreatico-duodenal cancer and portal hypertension, due stress is given to those fields in which recent endeavour has been most producti of advance.

An excellent chapter on 'Pulmonary Functiợn Studies in Relation to Chest Surgery' attempts deduce the value of estimates of lung volume, vitw capacity, oxygen saturation, bronchospirometry and similar information in assessing patients in whow thoracoplasty, lobectomy or some form of collap $\overline{\overline{s e}}$ therapy is contemplated. The main interest this contribution lies in the I I case studies which are reported in detail both as to their pre- and posere operative condition.

Richard Sweet draws from his wide experience in oesophageal surgery to contribute a comprehensige essay on this subject. 'This might have been of mote value had it been a little less comprehensive and, example, dealt only with resection for carcinom As it is, atresia of the oesophagus and achalasia at dealt with very briefly. The latter condition has not attracted the attention in American which it hể over here, and the form of cardioplasty reconia mended has been abandoned by most surgeons in Britain, as a long-term follow up of the patienss has shown the almost invariable occurrence of peptic ulcer at the suture line. On the subject of oesophagectomy for cancer however, Sweet is a master and his well-illustrated account of the operation most informative. His statistics, based on a pes sonal series of 394 patients, are most impressive. with a three year survival rate of 24 per cent. 응

The surgery of hypertension is covered by Snithwick in some 70 pages with all the clarity ang simplification which connote the good teaches, whilst Whipple contributes a short but thoughtf account of the physiology and pathology of portenl hypertension. $\mathrm{He}$ is an acknowledged authority की the subject, performed some of the first successf operations for it and gives a most interesting hi $\overrightarrow{\vec{e}}$ torical account with references.

The 'Treatment of Craniocerebral Injuries' the subject of one of the outstanding chapters of the book. Much research into the underlying physiology, pathology and mechanics of cerebral injury has led to a better appreciation of the sigh and symptoms in these patients. By gathering to gether in one article most of this recent work toe authors have done a great service.

Pulaski provides a neat account of the uses of streptomycin in surgery, whilst the chapter on skim grafting is valuable because it includes information on the use of stored skin, as well as of recent advances in cutting and applying grafts.

Lloyd Lewis's chapter on tumours of the tes is a monograph on the subject and represents thoo ideal contribution for such a symposium as the The author speaks with authority, having treated less than 109 seminomas and seen four examples off bilateral tumour. He gives a clear classification ared description of the pathology followed by section on the signs, symptoms, diagnosis and treatment.

The final chapter concerns pancreaticoduodenạ 
cancer and gives an excellent review of the subject from Whipple (1 935) to Cattell (1949).

The book is strongly commended, its only drawback being its price.

S.T.

\section{ADVANCES IN INTERNAL MEDICINE. VOL. III}

Edited by William Dock, M.D., and I. SNapper, M.D. Pp. xiii +478 . London and New York: Interscience Publishers. 1949. 68s.

It is the beauty of books such as this that they provide a reasonably understandable scientific basis for some of the clinical procedures and modern therapeutics that might otherwise be regarded purely as the outcome of empiricisms.

The section on BAL reviews the fascinating experimental work which established it as one of the mainstays in the treatment of metallic poisoning. The clinician will here receive the answer why he must maintain a very high blood concentration in the early stages of poisoning, as otherwise indeed the toxic effects might be enhanced.

Haemolytic anaemia is dealt with competently by Estren and Damashek. These two names assure a high standard, and one would have difficulty in finding a more concise and up to date summary.

Penicillin, streptomycin, histoplasmosis, antithyroid compounds, enzymic methods in diagnosis, plasma fractionation, acclimatization to heat and therapeutic agents in neurological disorders are the other subjects dealt with in this volume.

The standard throughout is high, the references extensive, and the paper and printing good. One might have wished for more detailed discussion of the therapeutic aspects of cerebro-vascular catastrophies, but perhaps that would go beyond the scope of the book. Altogether, not an easy book to read, but one which will fully repay the effort of the physician who has not lost the desire to enquire into the why and wherefore of medicine and therapy.

F.W.W.

\section{ENGLISH INDEX TO SOVIET MEDICAL PERIODICALS AVAILABLE IN LONDON LIBRARIES. VOL. I, I945-47}

By Donovan T. Richnell, B.A., F.L.A. Pp. xi 93. London: H. K. Lewis. 1950. £I.

The purpose of the above publication is to make more widely known current contributions of the Soviet Union to medical science, which aim it achieves very fully.

As the title says, it provides a guide to those journals which can readily be consulted in the main libraries in London. For this reason it is not a complete survey of all Soviet medical publications. Nevertheless, such a work, giving the title in Eng- lish, is of obvious importance to any research worker interested.

The work has been undertaken by the compiler, $\stackrel{\mathbb{D}}{\mathrm{C}}$ under the sponsorship of the Medical Committee of the Society for Cultural Relations, with the $\vec{F}$ knowledge that a good deal of work in Soviet medical journals, though the journals are available, has been inaccessible because they have not been indexed in $\frac{\bar{N}}{\bar{D}}$ any of the recognized reference works and very $\frac{\bar{\sigma}}{\vec{\nabla}}$ few are abstracted in the abstracting journals.

\section{PRINCIPLES OF OPHTHALMOLOGY}

By Thomson Henderson, M.D. Pp. 230, with $82 \vec{\omega}$ illustrations. London: William Heinemann. I950. 20s.

This small well-illustrated work is based upon studies of the comparative anatomy of ocular $-\omega$ structure in man and some 200 mammals of diverse orders, and the accounts given provide a welcome $\omega$ addition to the ophthalmologist's library. The clinical problems of accommodation and pressure anomalies are presented in fresh perspective against this background and, although the somewhat novel arguments with which the author supports his views of the pathogenesis of ocular hypertension are not likely to receive general assent, the student will find here a considerable amount of new material.

\section{MEDICAL ANNUAL, $195^{\circ}$}

\section{Bristol: John Wright and Sons Ltd.}

The standard expected of this annual has been maintained in the present edition. It is always a\% pleasure when new editions of the 'Medical $\stackrel{\odot}{\varrho}$ Annual' are published, and the reviewers have $\overrightarrow{\vec{B}}$ achieved balanced and impartial essays on their subjects. There are several interesting and im-? portant contributions in the present issue, including, amongst others, a review and extensive bibliography on geriatrics by Dr. Marjorie Warren, an article on certain aspects of social medicine and, what is a new feature in the annual, a section on 3 aviation medicine. There is also an interesting re-io view of work in connection with the thyroid gland, $\frac{O}{2}$ including the use of radio-active iodine and the thiouracil group of drugs. The indications foro operation in cases of congenital cardiovascular disease are also considered.

The book is, as usual, well illustrated and will be of wide interest to all specialists as well as to generalo practitioners. The publishers are to be con- $N$ gratulated on another well produced edition withN many helpful diagrams and illustrations. Every $\omega$ member of the profession would benefit by reading through this short and significant summary of the year's best contribution to medicine and surgery.

Not the least value in the book is the practitioner's? index of recent pharmaceutical preparations and medical and surgical appliances.

P.M. 